УДК 577.2

DOI: $10.33184 /$ spbgb-2021-09-21.12

\title{
Кортизол как биомаркер черт темперамента подростков
}

\author{
() М.И. Гарипова, С.А. Башкатов, Л.М. Хабибуллина
}

Башкирский государственный университет

Россия, Республика Башкортостан, 450076 г. Уфра, улица Заки Валиди, 32

\section{Email:margaritag@list.ru}

Нейрохимические биомаркеры черт темперамента различаются по своей природе и влиянию на поведение в разных возрастных группах. В статье рассматривается роль кортизола в формировании особенностей темперамента подростков.

Ключевые слова: биомаркеры черт темперамента, кортизол, расстройства пищевого поведения, нейротизм.

Наибольшее количество публикаций, посвященных эндокринным биомаркерам черт темперамента в подростковом возрасте посвящено исследованию концентрации кортизола. Кортизол - основной глюкокортикоид человеческого организма, отвечает за обеспечение мозга глюкозой. Концентрация кортизола в крови определяется временем суток и ситуацией, в том числе стрессом. Регуляция синтеза и секреции кортизола обеспечивается осью НРА и зависит от функционального состояния коры надпочечников. Секреция кортизола снижается при хроническом стрессе вследствие истощения коры надпочечников. Результаты ряда исследований свидетельствуют о том, что гипокортицизм сопровождается усилением таких черт характера, как невротизм и интроверсия. По данным Вооіј SH и соавторов, в этом случае наблюдается относительно более плоская кривая суточной концентрации кортизола [1]. Концентрации кортизола, определенные в момент пробуждения, согласно исследованиям S. Dockray, положительно коррелируют с таким свойством личности, как открытостью опыту [2]. Открытость опыту наряду с экстраверсией, доброжелательностью, добросовестностью и невротизмом входит в перечень личностных черт, входящих в состав «Большой пятерки» [3]. Ряд авторов приходит к выводу о повышенной активности оси HРА при депрессии, связанной с гиперкортизолемией [4]. По данным Вооіј SH и соавторов, более высокие концентрации кортизола связаны с более высокими уровнями избегания вреда и более низкими уровнями поиска новизны [4]. Таким образом, индивидуальные особенности подростка, эмоциональная лабильность или стабильность, оказывают существенное влияние на секрецию кортизола, устойчивость к стрессу и фрормирование его отсроченных последствий. Индивидуальная реакция на стресс может быть связана с различным состоянием систем крови, депонирующих и транспортирующих кортизол [5]. Исследования Booij и Stroud и соавторов показывают, что реакции кортизола на однократное воздействие психосоциального стресса, а также циркадные паттерны свободного кортизола в слюне не отличаются у испытуемых с высокими или низкими баллами по экстраверсии, нейротизму или психотизму [4]. По мнению ряда авторов, использование АКТГ в качестве показателя не выявило различий между испытуемыми с разной выраженностью психологических черт. Вероятно, это связано с тем, что АКТГ отражает ежедневную активность оси НРА и применим для выявления эндокринной патологии [6].

Примечательно, что маркером многих проблем подросткового возраста является дисбаланс кортизола и стероидных гормонов. Согласно Oskis A и соавторам, анорексия 
коррелирует с повышенной секрецией кортизола и дегидроэпиандростерона [7]. Экспериментальные данные указывают на нарушение регуляции фрункции оси Гипоталамус-Гипофиз-Надпочечники при анорексии у подростков, о чем свидетельствует гиперсекреция как кортизола, так и дегидроэпиандростерона. Дегидроэпиандростерон является предшественником андрогенов и эстрогенов, синтез которых завершается в периферических тканях. Увеличение концентрации половых стероидов нарушает регуляцию оси HPG и может быть причиной нарушения регуляции [8]. Этот вывод подтверждается данными Luz Neto и соавторов, из которых следует, что у подростков с расстройствами пищевого поведения, особенно нервной анорексией, повышен уровень кортизола [9]. Dockray и соавторы [10] исследовали депрессию, реактивность кортизола и ожирение в детском и подростковом возрасте. Результаты показали, что депрессия связана с более высоким индексом массы тела и повышенной секрецией кортизола в ответ на стресс. Обобщенные, эти данные подчеркивают, что кортизол может оказывать влияние в подростковом возрасте на развитие личностных черт и поведенческих синдромов. Наиболее значимым является значение концентрации кортизола, определяемое вскоре после пробуждения. Повышенная интроверсия была связана с более низкими реакциями на пробуждение кортизола как у мужчин, так и у женщинучастников [11]. Экстраверсия в значительной степени предсказывала общую концентрацию кортизола в момент пробуждения. Женщины демонстрировали большую общую реакцию на пробуждение кортизола, чем мужчины [11]. Динамика концентрации кортизола в слюне или в крови в течение дня с момента пробуждения до засыпания также имеет диагностическое значение. Было показано, что более ровные ритмы коризола в течение дня бодрствования коррелируют с более высоким нейротизмом у обследуемых мужского пола [10].

\section{Литература}

1. Booij SH, Bouma EM, de Jonge P, Ormel J, Oldehinkel AJ.: Chronicity of depressive problems and the cortisol response to psychosocial stress in adolescents: the TRAILS study. Psychoneuroendocrinology 2013, 38(5):659666. doi: 10.1016/j.psyneuen.2012.08.004.

2. Samantha Dockray, Elizabeth J. Susman, Lorah D. Dorn: Depression, Cortisol Reactivity, and Obesity in Childhood and Adolescence. Journal of Adolescent Health 2009, 45: 344-350. doi.org/10.1016/j.jadohealth.2009.06.014

3. Sundin, Zachary \& Chopik, William \& Welker, Keith \& Ascigil, Esra \& Brandes, Cassandra \& Chin, Kristi \& Ketay, Sarah \& Knight, Erik \& Kordsmeyer, Tobias \& McLarneyVesotski, Amber \& Prasad, Smrithi \& Reese, Zachary \& Roy, Ashlin \& Sim, Lester \& Stern, Julia \& Carré, Justin \& Edelstein, Robin \& Mehta, Pranjal \& Penke, Lars \& Tackett, Jennifer: (2021). Estimating the Associations between Big Five Personality Traits, Testosterone, and Cortisol. Adaptive Human Behavior and Physiology 2021. doi./10.1007/s40750-020-00159-9.

4. Booij SH, Bouma EM, de Jonge P, Ormel J, Oldehinkel AJ.: Chronicity of depressive problems and the cortisol response to psychosocial stress in adolescents: the TRAILS study. Psychoneuroendocrinology 2013, 38(5):659666. doi: 10.1016/j.psyneuen.2012.08.004.

5. Garipova M.I., Shigapova A.I., R.G.Farkhutdinov, V.V. Fedyaev, J. M. Sotnikova, A.B. Yakupova.: The distribution of 3,5,30-triiodothyronine between the transport systems of blood and nuclei of the tissues. Journal of biomolecular structure and dynamics 2019, 37(s1): 4445 doi 10.1080/07391102.2019.1604468 
6. Samantha Dockray, Elizabeth J. Susman, Lorah D. Dorn: Depression, Cortisol Reactivity, and Obesity in Childhood and Adolescence. Journal of Adolescent Health 2009, 45: 344-350. doi.org/10.1016/j.jadohealth.2009.06.014

7. Oskis A, Clow A, Thorn L, Loveday C, Hucklebridge F.: Differences between diurnal patterns of salivary cortisol and dehydroepiandrosterone in healthy female adolescents. Stress 2012, 15(1):110-114. doi: 10.3109/10253890.2011.582529.

8. Catherine B. Stroud, Frances R. Chen, Leah D. Doane, Douglas A. Granger: Individual differences in early adolescents' latent trait cortisol (LTC): Relation to early adversity. Developmental Psychology 2016,_58_6): 700-713.

9. Luz Neto LMD, Vasconcelos FMN, Silva JED, Pinto TCC, Sougey ÉB, Ximenes RCC.: Differences in cortisol concentrations in adolescents with eating disorders: a systematic review. J Pediatr (Rio J). 2019, 95(1):18-26. doi: 10.1016/j.jped.2018.02.007.

10. Dockray S., Elizabeth J. Susman, Lorah D. Dorn: Depression, Cortisol Reactivity, and Obesity in Childhood and Adolescence. 2009, 344350.doi.org/10.1016/j.jadohealth.2009.06.014

11. Condon E: Psychosocial Influences on Acceptability and Feasibility of Salivary Cortisol Collection From Community Samples of Children. Res Nurs Health 2016, 39(6):449-462. doi: 10.1002/nur.21744. Epub 2016 Sep 30.

\title{
Cortisol as a biomarker of adolescent temperament traits
}

\author{
M.I.Garipova, S.A. Bashkatov, L.M. Habibullina \\ Bashkir State University \\ 32 ZakiValidi Street, 450076 Ufa, Republic of Bashkortostan, Russia
}

^Email:margaritag@list.ru

Neurochemical biomarkers of temperament traits differ in their nature and influence on behavior in different age groups. The article considers the role of cortisol in the formation of the adolescent's temperament traits.

Keywords: biomarkers of temperament traits, cortisol, eating disorders, neuroticism. 